Outgroup Morality Perceptions Mediate Secondary Transfer Effects from Direct and Extended Contact: Evidence from Majority and Minority Group Members

Loris Vezzali ${ }^{\mathrm{a}}$, Gian Antonio Di Bernardo ${ }^{\mathrm{a}}$, Michèle D. Birtel ${ }^{\mathrm{b}}$, Sofia Stathi ${ }^{\mathrm{b}}$, Marco Brambilla ${ }^{\mathrm{c}}$ ${ }^{a}$ University of Modena and Reggio Emilia, Department of Education and Humanities, Italy ${ }^{b}$ University of Greenwich, UK Department of Psychology, Social Work and Counselling, UK ${ }^{c}$ University of Milano-Bicocca, Department of Psychology, Italy

Author Note

Correspondence concerning this article should be addressed to Loris Vezzali, University of Modena and Reggio Emilia, Viale Allegri 9, 42121, Reggio Emilia, Italy. Email: loris.vezzali@unimore.it. 


\title{
Outgroup Morality Perceptions Mediate Secondary Transfer Effects from Direct and Extended Contact: Evidence from Majority and Minority Group Members
}

\begin{abstract}
The 'secondary transfer effect' (STE), defined as contact with a primary outgroup improving attitudes towards a secondary outgroup uninvolved in contact, has mainly been studied with reference to direct contact and considering attitude generalization as the main mediating mechanism. Using a majority (422 Italians) and minority (130 immigrants) adolescent sample from high-schools in Italy, we examined outgroup morality perceptions as a new mediating mechanism, and tested for the first time whether the STE emerges for extended contact. Results revealed that the STE emerged for direct contact among the majority group and for extended contact among the minority group, and it was sequentially mediated by perceptions of morality towards the primary outgroup, and by attitudes towards the primary outgroup and perceptions of morality towards the secondary outgroup. The STE also emerged for direct contact among the minority group, with morality perceptions towards the secondary outgroup and attitudes towards the primary outgroup being parallel mediators. We discuss the theoretical implications of the findings, arguing that it is important to identify the conditions and underlying processes of the STE in order to reduce prejudice in the case of both majority and minority groups.
\end{abstract}

Keywords: intergroup contact, extended contact, secondary transfer effect, morality, prejudice reduction, generalized prejudice 
The growing cultural and social diversity in today's societies raises intergroup concerns and feelings of threat among both majority and minority group members (Chang, Krosch, \& Cikara, 2016; Stephan \& Stephan, 2000; Trawalter, Richeson, \& Shelton, 2009). Meaningful contact between members of different groups (Allport, 1954; Pettigrew \& Tropp, 2006) has been shown to promote positive intergroup relations. However, not everyone has opportunities for contact with minority groups due to educational and residential segregation (Birtel, Reimer, Wölfer, \& Hewstone, 2019), as for example in Northern Ireland and Cyprus. Additionally, even when there are opportunities for intergroup contact, ingroup members tend to avoid contact with outgroup members (Al Ramiah, Schmid, Hewstone, \& Floe, 2015; Stephan \& Stephan, 1985). Furthermore, intergroup distinctions stem from various characteristics, such as ethnicity and health/disability, and these characteristics can form the basis of stigmatization. With increased immigration (United Nations, 2015) and disability rates (World Health Organization, 2018), we need to understand how to effectively reduce prejudice towards different types of stigmatized groups.

Research has consistently shown that direct contact is not necessary for prejudice reduction, and that the potential of contact can also emerge when contact is indirect, that is when it is not face-to-face. Previous research has demonstrated the positive effects of indirect forms of contact on intergroup relations, such as extended contact (i.e., knowing that ingroup members have outgroup friends; Birtel, Vezzali, \& Stathi, 2018; Vezzali, Hewstone, Capozza, Giovannini, \& Wölfer, 2014; Wright, Aron, McLaughlin-Volpe, \& Ropp, 1997; Zhou, Page-Gould, Aron, Moyer, \& Hewstone, 2018). But the potential of contact, and specifically the potential that contact has to reduce prejudice, can also be realized through generalization processes, and specifically through generalization from the outgroup one has contact with (primary outgroup) to 
an uninvolved outgroup (secondary outgroup); this phenomenon is called 'secondary transfer effect' (STE; Pettigrew, 1998, 2009).

Adding to the potential for extended contact to reduce prejudice, and for the STE to extend these benefits to groups uninvolved in direct or indirect (i.e., extended) contact, the present research considers three key gaps in the literature. Firstly, while there are studies showing the STE for direct contact (for a review, see Lolliot et al., 2013), research that combines indirect (i.e., extended) contact with the benefits provided by the STE is surprisingly scarce. In addition to contributing to this scarce literature, we test for the first time whether the STE manifests for extended contact, and we examine this both for majority and minority group members. Secondly, research has mainly focused on attitudes as the main explanation for the STE (for a review see Lolliot et al., 2013), but also on intergroup emotions (Giovannini \& Vezzali, 2011; Vezzali \& Giovannini, 2012) and individual differences (Shook, Opkins, \& Koech, 2016; Vezzali, et al., 2018). It has, however, neglected variables strongly related to impression formation like morality perceptions (Brambilla \& Leach, 2014). In examining morality perceptions, we also address a relevant gap in the contact literature, which only recently has started to test outgroup morality as a mediator of contact effects (Brambilla, Hewstone, \& Colucci, 2013). Thirdly, in order to achieve a long-lasting change in relations between ingroup and outgroup members, behavioral variables, or relevant behavioral proxies, need to be taken into account as outcome variables in addition to attitudes.

In the present article, we tested the STE in an ethnic majority and minority adolescent sample in Italy. We examined whether contact improves attitudes and contact intentions between Italians and immigrants, and whether these positive effects generalize to a secondary, dissimilar outgroup, i.e., disabled people (STE). In order to address the aforementioned gaps in the 
literature, we examined the independent STEs for both direct and extended contact. Furthermore, we tested a new mediator, outgroup morality perceptions. Importantly, to consider more proximal behavioral outcomes, we measured intentions to engage in contact with the secondary outgroup. We are currently not aware of other studies testing contact intentions as the outcome of the STE. Via the above, we provide a significant contribution to understanding the potential of direct and extended contact to reduce prejudice towards primary and secondary outgroups, as well as the processes that explain this.

\section{The Secondary Transfer Effect of Intergroup Contact}

There is impressive evidence for Allport's (1954) intergroup contact theory, showing that positive contact with outgroup members reduces prejudice (Pettigrew \& Tropp, 2006; Vezzali \& Stathi, 2017). Generalization processes facilitate contact effects (Pettigrew, 1997, 1998, 2009). In his seminal work, Pettigrew (1998) outlines three types of generalization of contact effects: from the outgroup member to the outgroup as a whole, across contact situations, and to outgroups not involved in the initial contact situation (i.e., STE, Pettigrew, 2009; for review see Lolliot et al., 2013). Despite the powerful effects of contact on intergroup relations, studies have mainly focused on the first two types of generalization, and there has been relatively limited research on the STE. We note, however, that in recent years a consistent body of evidence documented the existence of the STE (e.g., Brylka, Jasinskaja-Lahti, \& Mahonen, 2016; Lissitsa \& Kushnirovich, 2018; Mahonen \& Jasinskaja-Lathi, 2016; Meleady \& Forder, 2018; Schmid, Hewstone, Kupper, Zick, \& Wagner, 2012; Schmid, Hewstone, \& Tausch, 2013; Shook et al., 2016; Tausch et al., 2010; Vezzali et al., 2018). Although research so far has provided convincing evidence for the STE, there is a need to examine relevant underlying processes, whether it occurs both for 
majority and minority group members alike, and whether indirect forms of contact, such as extended contact, can also produce it.

\section{Extended Contact and the Secondary Transfer Effect}

Indirect forms of contact, such as knowing that an ingroup member is friends with an outgroup member (extended contact), and observing an intergroup interaction (vicarious contact) (Vezzali et al., 2014; Zhou et al., 2018), or imagining positive contact (Crisp \& Turner, 2013; Miles \& Crisp, 2014) are effective means of improving intergroup relations. While most of the research has examined the STE in the context of direct contact (Lolliot et al., 2012), there is some evidence for its existence in the case of vicarious (Joyce \& Harwood, 2014) and imagined contact too (De Carvalho-Freitas \& Stathi, 2017; Harwood, Paolini, Joyce, Rubin, \& Arroyo, 2011; Visintin, Birtel, \& Crisp, 2017). However, research has not yet examined if extended contact can lead to the STE. Schmid et al. (2012) included a measure of extended contact but used a combined measure of direct and extended contact to analyze the STE, therefore it is not possible to disentangle the effects of direct from those of extended contact.

Our first aim was to test whether extended contact generalizes to secondary outgroups among majority and minority group members. While direct contact effects tend to be less strong for minority (effect size $r=-.18$ ) than majority (effect size $r=-.23$ ) group members (Tropp \& Pettigrew 2005), extended contact effects do not appear to differ significantly in their effect size between majority $(r=.23)$ and minority $(r=.22)$ group members (Zhou et al., 2018). In line with these meta-analytic results, the STE was found for the majority group's contact with the minority, but not for the minority group's contact with the majority (Van Laar, Levin, Sinclair, \& Sidanius, 2005; Vezzali et al., 2018). In our study, we examined the STE for both majority and 
minority group members, by considering different types of contact; we predicted to find the STE for direct contact among majority group members, and for extended contact among both groups.

According to research findings, the STE tends to be stronger for secondary outgroups that are similar to the primary outgroup (Harwood et al., 2011; Joyce \& Harwood, 2014), but also occurs for dissimilar outgroups (e.g., Schmid et al., 2012, ethnicity to sexual orientation; Tausch et al., 2010, religion to ethnicity). In our study, we tested whether the STE manifests for dissimilar groups, generalizing from positive attitudes towards a different ethnic group to people with disability (see also Vezzali et al., 2018). Going a step further, we tested whether this generalization occurs not only for direct but also for extended contact.

\section{Processes Underlying the Secondary Transfer Effect}

Research has generally focused on outgroup attitudes as the main mediator of the STE, that is contact with the primary outgroup is associated with more positive attitudes towards the secondary outgroup, mediated by positive attitudes towards the primary outgroup (Brylka et al., 2016; Pettigrew, 2009; Schmid et al., 2012, 2013; Tausch et al., 2010; Vezzali \& Giovannini, 2012).

For example, Tausch et al. (2010) demonstrated in three cross-sectional studies (Cyprus, Northern Ireland, Texas) and one longitudinal study (Northern Ireland), with overall 4,312 participants, that contact with the primary outgroup is associated with reduced prejudice towards a secondary outgroup via more positive attitudes towards the primary outgroup. Furthermore, Vezzali and colleagues showed that the STE, via attitude generalization, also occurs among adolescents (Vezzali \& Giovannini, 2012), and even among elementary school children (Vezzali et al., 2018) from the ethnic majority (but not minority) group. 
While the basic attitude generalization effect of contact is now established, not much is yet known about additional underlying processes of the STE. Recent research indicates that processes other than attitude generalization may play a role. For example, intergroup emotions, which are the key mediators of the contact-prejudice relationship (i.e., intergroup anxiety and empathy; Pettigrew \& Tropp, 2008), can also explain the generalization of positive attitudes to secondary outgroups (Giovannini \& Vezzali, 2011; Vezzali \& Giovannini, 2012). Additionally, there is some evidence that the STE can be explained by individual differences such as social dominance orientation (Shook et al., 2016; Vezzali, Di Bernardo et al., 2018). Evidence considering other mediators, such as ingroup identification, is mixed (Pettigrew, 2009; Schmid et al., 2013). Therefore, there is a need to understand the processes of the STE beyond the mediating role of intergroup attitudes. As such, we argue that perceptions regarding the morality of the outgroup could play an important role in explaining the positive effect of contact on secondary outgroups.

\section{Outgroup Morality Perceptions as a Mediator of Contact Effects}

Morality refers to principles and values that indicate whether a behavior towards others is right or wrong, and it drives interpersonal and intergroup perceptions (Brambilla \& Leach, 2014). Morality influences how people feel about themselves (Rodriguez Mosquera, Manstead, \& Fischer, 2002) and how they act (Schwartz, 1992). When evaluating others based on their perceived traits, various dimensions such as sociability, morality and competence can be considered. While sociability refers to the ease of forming a connection with others (e.g., friendliness), morality informs how (un)trustworthy and threatening someone is (Brambilla, Biella, \& Freeman, 2018; Leach, Ellemers, \& Barreto, 2007). 
Research has shown that morality drives person and group impression formation (Brambilla \& Leach, 2014). For example, Brambilla, Rusconi, Sacchi, and Cherubini (2011) found that, when forming impressions of others, people have a greater tendency to gather information about the morality rather than the sociability or competence of a social target, as morality is highly informative of others' intentions. In a similar vein, moral information is more critical than information about sociability or competence in determining the overall impression that people form of other individuals and groups (Brambilla, Sacchi, Rusconi, Cherubini, \& Yzerbyt, 2012). Importantly, morality not only affects impression formation, but also interpersonal (Brambilla, Sacchi, Menegatti, \& Moscatelli, 2016) and intergroup behavior (Brambilla, Sacchi, Pagliaro, \& Ellemers, 2013). As such, Brambilla et al. (2013) manipulated moral qualities of ingroup and outgroup targets. In general, participants reported lower intentions to interact with targets that were perceived as lower in moral traits, which was mediated by perceived threat. For ingroup members, the immoral target was perceived as a threat to the ingroup image, for outgroup members the target was perceived as a threat to the ingroup's safety. Moreover, impressions are more polarized when individuals evaluate others' morality rather than other characteristics (Brambilla, Carraro, Castelli, \& Sacchi, 2019). Taken together, these studies show that morality perceptions are important predictors of interpersonal and intergroup attitudes (Brambilla \& Leach, 2004).

Despite its importance in regulating interpersonal and intergroup interactions, outgroup morality has been overlooked in intergroup contact research as a potential mediator of the contact effects, with the exception of two studies that examined attitudes towards minority group members. Brambilla et al. (2013) found that Italians' contact with immigrants was associated with greater perceptions of immigrants as competent, sociable and moral, as well as with greater 
intentions to support actions for social change. Importantly, only outgroup morality mediated the effect of contact on social change intentions. Vezzali, Brambilla, Giovannini, and Colucci (2017) found that direct and extended cross-group friendships of Italian high-school students with homosexuals were associated with greater intentions to interact with homosexuals. This effect of contact on sexual prejudice was mediated by a component of morality, and specifically by higher perceived moral purity of homosexuals. Extending these studies, we tested whether outgroup morality mediates the effects of direct and extended contact on intergroup attitudes and behavioral intentions among both majority and minority group members, and whether outgroup morality also explains the STE.

Based on the reviewed literature, which shows that morality perceptions drive the formation of attitudes, including intergroup attitudes, and mediate contact effects, we predict that perceived morality of the primary outgroup will mediate the effects of (direct and extended) contact on attitudes towards the primary outgroup, and in turn, on attitudes towards the secondary outgroup.

In addition, we predict that perceived morality of the primary outgroup will mediate the contact effects on perceived morality of the secondary outgroup, and in turn on attitudes towards the secondary outgroup. As reported above, prior research has shown that outgroup morality has a powerful role in predicting intergroup impressions and attitudes (Brambilla et al., 2012). In a similar vein, the perception that an outgroup is moral might generalize to a secondary outgroup (that shares the characteristic of stigmatization with the primary outgroup) because of an enhanced perception that intergroup relations are generally governed by shared moral values. In other words, intergroup contact can increase the attribution of morality to the outgroup, and at the same time enhance the perception that groups with distinct identities can also be moral. This, 
consequently, facilitates the attribution of morality to secondary outgroups, and in turn more positive attitudes towards secondary outgroups.

\section{The Present Research}

In the present study we sought to examine whether intergroup contact experiences between ethnic majority (Italian) and minority (immigrant) adolescents generalize to attitudes towards a secondary, dissimilar but also stigmatized outgroup (i.e., disabled people). The model we tested is depicted in Figure 1. We argue that our study is novel in three ways.

Firstly, in relation to the STE, we not only considered direct contact (i.e., cross-group friendships) in line with previous research, but also extended contact for both ethnic majority and minority group members. Only one previous study (Schmid et al., 2012) considered extended contact and the STE; however, extended contact was combined with direct contact into one measure, and thus the unique effect of extended contact was not tested.

Secondly, in addition to intergroup attitudes (to be consistent with past literature), we tested a new mediator of the contact-attitudes relationship, outgroup morality perceptions, for both the primary and the secondary outgroup.

Thirdly, in addition to attitudes towards the secondary outgroup (which represents a classic dependent variable in the STE research), since intention is a more proximal predictor of behavior than attitudes (Fishbein \& Ajzen, 1974), we measured intentions to have contact with the secondary outgroup as an outcome variable. This way, our study tested the generalization of contact effects on a variable that is more proximal to behavior and its underlying processes.

We made the following predictions:

H1: the STE should emerge among majority members as an outcome of direct contact, and among both majority and minority members as an outcome of extended contact. 
H2: Effects of direct (for the majority group members only) and extended contact on attitudes and contact intentions towards the secondary outgroup should be sequentially mediated by increased perceptions of morality towards the primary outgroup (first-level mediator), and by improved attitudes towards the primary outgroup and morality of the secondary outgroup (second-level mediators) (Figure 1).

To be conservative, we controlled for direct and extended contact with the secondary outgroup to rule out the possibility that effects could be explained at least in part by the fact that individuals with more contact with the primary outgroup also have more contact with the secondary outgroup (Schmid et al., 2013; Vezzali \& Giovannini, 2012).

\section{Method}

\section{Participants and Procedure}

Five hundred and fifty-eight students from seven high schools located in Northern Italy took part to the research. Individuals with intellectual disabilities, as indicated by teachers, were excluded from the administration of the questionnaire as they might have encountered difficulties in completing the questionnaire. Six immigrant participants were excluded from the analysis because of high levels of missing data (>20\%). Thus, the final sample consisted of 552 respondents, namely 422 Italians (225 males, 197 females; $\left.M_{\text {age }}=17.20, S D=1.10\right)$ and 130 immigrants (55 males, 75 females; $M_{\text {age }}=17.61, S D=1.42$ ). The distinction between Italians and immigrants was made on the basis of school indications, taking into account whether children had parents of foreign (i.e. non-Italian) origin. Regarding the origin of the immigrant sample, the most represented birth continents were Asia (36.2\%), followed by Africa (31.5\%) and (Eastern) Europe (25.4\%).

The sample size for the majority group (i.e., Italians) allowed reaching a power for conducting a mediation analysis of at least 0.8 to detect a small effect size (Fritz \& MacKinnon, 
2007). The smaller sample size of the minority group (i.e., immigrants) instead allowed reaching a power of 0.75 to detect a small effect size.

Participants completed a questionnaire that was distributed during class hours. In the Italian version, the primary outgroup target was immigrants; in the version for immigrants, Italians were the primary outgroup. All participants completed the questionnaire in the Italian language.

\section{Measures $^{1}$}

Direct contact with the primary and secondary outgroup. Five items considering students' cross-group friendships, an especially powerful form of contact (Davies, Tropp, Aron, Pettigrew, \& Wright, 2011; Turner, Hewstone, Voci, Paolini, \& Christ, 2007), were used for assessing direct contact of the ingroup with the primary and secondary outgroup. In particular, participants were asked how many primary and secondary outgroup friends they have (responses ranged from 1 "none" to 5 "a lot"), and how many friends they have among immigrants [Italians] and among individuals with disabilities a) in general, b) at school, c) in the neighborhood, and d) during free time. Responses were: 1 (none), 2 (from 1 to 2 friends), 3 (from 3 to 4 friends), 4 (from 5 to 6 friends), and 5 (more than 6 friends). Items were combined to form reliable measures of direct contact with primary or secondary outgroup members (alphas $=.88$ and .73 for primary and secondary outgroup, respectively).

Extended contact with primary and secondary outgroup. Five parallel items were created for assessing extended contact. Similar to the direct measure, participants were asked to indicate how many of their friends had an immigrant [Italian] or an individual with disability as friend, in general (two items), at school, in the neighborhood, and during the free time (see Lolliot et al., 2015; Tausch, Hewstone, Schmid, Hughes, \& Cairns, 2011; Turner, Hewstone, Voci, \& Vonofakou, 2008). Response scales were identical to the direct friendship items above. 
We averaged items to obtain indices of extended contact towards primary (alpha $=.90)$ and secondary (alpha $=.85)$ outgroup.

Morality of the primary and secondary outgroup. Primary and secondary outgroup perceptions of morality were measured using three items taken from Brambilla et al. (2013). In particular, participants were asked to rate how much they perceived the outgroups as "honest," "trustworthy," and "sincere." On the 5-step scale, 1 corresponded to "not at all" and 5 to "very much". We obtained indices of morality towards primary $($ alpha $=.91)$ and secondary (alpha $=.91$ ) outgroup by averaging respective items.

Attitudes towards the primary and the secondary outgroup. A feeling thermometer was employed in order to evaluate both the primary and the secondary outgroup (based on Haddock, Zanna, \& Esses, 1993). Specifically, respondents indicated, on a graphic thermometer, their attitudes towards immigrants [Italians] and towards individuals with disability. Responses ranged from 0 (extremely negative) to 100 (extremely positive) with 50 (neither positive, nor negative) as the neutral point.

Contact intentions towards the secondary outgroup. Three items measuring contact intentions adapted from Mackie, Devos, and Smith (2000; see also Turner, West, \& Christie, 2013) were used. Participants were asked to think about the next time they would meet a person with disability and to rate how likely they would be to a) start a conversation, b) be interested in starting a conversation and c) wish to start a conversation. Responses ranged from 1 (not at all) to 5 (very much). Items were averaged in a single index of contact intentions towards the secondary outgroup (alpha $=.91)$. 


\section{Results}

Descriptive statistics and correlations for Italians and immigrants are presented in Table 1 and Table 2 respectively. Overall, minority members had more outgroup friends than majority members, both with respect to direct and extended contact; conversely, majority members had more friends among the secondary outgroup than minority members, but no differences emerged regarding extended contact. Regarding morality, minority members perceived the outgroup as more moral compared with majority individuals; on average, secondary outgroup members were rated more moral by the majority than by the minority sample. Concerning attitudes towards the primary outgroup, the minority rated the outgroup more positively than the majority; in any case, attitudes towards the primary outgroup were positive for both samples since means are significantly different from the neutral point of the scale $(t \mathrm{~s}>5.94, p<.001)$. Regarding attitudes towards the secondary outgroup, no differences emerged between Italians and immigrants in evaluating individuals with disability; in addition, as for the primary outgroup, both samples reported positive attitudes towards the secondary outgroup $(t \mathrm{~s}>8.02, p<.001)$. No differences emerged regarding contact intentions towards the secondary outgroup.

Hypotheses were tested by employing structural equation models with LISREL (Jöreskog \& Sörbom, 2007). In particular, contact measures (direct and extended contact with the primary outgroup) represented the exogenous variables; morality ascribed to the primary outgroup represented the first level mediator; attitudes towards the primary outgroup, along with morality of the secondary outgroup, were the second level mediators; contact intentions and attitudes towards the secondary outgroup were the dependent variables. The direct paths from direct and extended contact to second-level mediators and to dependent variables were estimated. Direct and extended contact with the secondary outgroup and gender ${ }^{2}$ were included as covariates in the 
model, that is all the paths from the covariates to mediators and dependent variables were estimated.

Model fit evaluation was assessed by employing the indexes suggested by $\mathrm{Hu}$ and Bentler (1999; see also Kline, 1998). Specifically, a $\chi^{2} / d f$ lower than 3, a CFI greater than .95, a SRMR equal or smaller than .08, and a RMSEA equal or smaller than .06. Significance of the indirect effects was tested by using bootstrapping procedures with 5,000 resamples.

\section{Majority Sample}

For the majority sample, a structural equation model with latent variables was applied (Table 3, Figure 2). For each latent construct two indicators were created following the indications by Little and collaborators (Little, Cunningham, Shahar, \& Widaman, 2002), with the exception of the attitude towards primary and secondary outgroup measures that composed of single items. In this latter case, the corresponding latent factor loaded a single indicator with the relative error fixed to 0 . Direct and extended contact with the secondary outgroup and gender were controlled for (morality, attitudes and contact intentions towards the secondary outgroup were regressed onto both direct and extended contact with the secondary outgroup).

The proposed model presented a good fit to the data, $\chi^{2}(81)=136.75, p<.001, \chi^{2} / d f=$ $1.69, \mathrm{RMSEA}=.04, \mathrm{CFI}=0.99, \mathrm{SRMR}=.03$. As can be seen in Figure 2, direct contact was associated with both morality and attitudes towards the primary outgroup. Morality towards the primary outgroup was in turn positively related to attitudes towards the primary outgroup and to morality ascribed to the secondary outgroup. Finally, both attitudes towards the primary outgroup and morality of the secondary outgroup were positively associated with increased contact intentions and with more favorable attitudes towards the secondary outgroup. 
Table 4 reports the results of the bootstrapping analyses. Direct contact with the primary outgroup was positively associated with contact intentions and attitudes towards the secondary outgroup through the indirect effect of enhanced morality of the primary outgroup and, in turn, attitudes towards the primary outgroup and morality of the secondary outgroup. These findings partially support H1 (effects did not emerge for extended contact) and are consistent with H2.

In addition to the hypothesized model, we tested one plausible alternative model. The first level mediators were morality of the primary outgroup and attitudes towards the primary outgroup, while the dependent variables were morality of the secondary outgroup, contact intentions and attitudes towards the secondary outgroup. In fact, it is possible that morality of the primary outgroup and attitudes towards the primary outgroup work as parallel mediators. The model showed a good fit to data, although not as good as that of our proposed model, $\chi^{2}(82)=$ 227.79, $p<.001, \chi^{2} / d f=2.78, \mathrm{RMSEA}=.06, \mathrm{CFI}=0.97, \mathrm{SRMR}=.03$. To compare our proposed model with this first alternative model, we used Akaike's (1987) information criterion (AIC) index, where lower scores indicate better fit. Specifically, we obtained AIC $=277.27$ for our proposed model, versus $\mathrm{AIC}=360.21$ for this alternative model.

\section{Minority Sample}

The same model illustrated in Figure 1 was tested with the immigrant sample. In line with the analysis performed for the majority sample, direct and extended contact with the secondary outgroup and gender were controlled for. Due to the lower number of participants, structural equation modelling was applied with observed variables.

Goodness-of-fit indexes showed an excellent fit, $\chi^{2}(4)=3.76, p=.44, \chi^{2} / d f=0.94$, $\mathrm{RMSEA} \approx .00, \mathrm{CFI}=1.00, \mathrm{SRMR}=.02$. From Table 5 and Figure 3 , it emerges that direct contact with the primary outgroup was positively associated with attitudes towards the primary 
outgroup and with morality towards the secondary outgroup. Extended contact with the primary outgroup was positively associated with morality towards the primary outgroup; in turn, this variable was positively associated with attitudes towards the primary outgroup and morality towards the secondary outgroup; attitudes towards the primary outgroup were related to attitudes towards the secondary group. Finally, morality towards the secondary outgroup was positively associated with both contact intentions and attitudes towards the secondary outgroup.

Inspection of indirect effects (Table 6) reveals that, consistent with $\mathrm{H} 1$, both direct and extended contact effects generalize to the secondary outgroup. In addition, partially in line with $\mathrm{H} 2$, the effects of extended contact are sequentially mediated by perceptions of morality towards the primary outgroup, and attitudes towards the primary outgroup and morality towards the secondary outgroup. In addition, the effects of direct contact generalize both via morality perceptions and intergroup attitudes.

To rule out alternative explanations, we tested the same alternative model as in the case of the majority sample. Fit indices were almost acceptable, $\chi^{2}(5)=15.25, p<.01, \chi^{2} / d f=3.05$, $\mathrm{RMSEA}=.12, \mathrm{CFI}=.98, \mathrm{SRMR}=.04 . \mathrm{AIC}$ of the alternative model was higher $(113.88)$ than that of the hypothesized model (105.71), suggesting the better fit of the latter compared to the former.

\section{Discussion}

The present research aimed at examining whether (a) the STE emerges as an outcome of not only of direct but also extended contact, (b) the STE emerges among both majority and minority group members, (c) outgroup morality perceptions are an underlying mechanism of the STE, in addition to attitude generalization. We also tested for the first time whether the STE occurs for behavioral intentions towards the secondary outgroup, in addition to attitudes towards 
the secondary outgroup. Importantly, we provided a stringent test of the STE, by considering dissimilar primary (based on ethnicity) and secondary (based on disability) outgroups, and by controlling for contact with the secondary outgroup.

Extending previous studies demonstrating the emergence of the STE for direct contact among majority groups (Van Laar et al., 2005; Vezzali et al., 2018) and high-status minority groups (Brylka et al., 2016), in our study the STE emerged as an outcome of direct contact both for the majority and the minority sample. In line with literature on the STE (Lolliot et al., 2013), results replicated evidence of the effect via attitude generalization. These findings are partly in contrast with our prediction that the STE would not emerge for direct contact in the case of the minority group, based on literature showing that contact is more effective for majority than for minority group members (Tropp \& Pettigrew 2005). However, this unexpected finding can be explained at least in part by the fact that, although less effective, contact in many cases is effective for the minority group (cf. Tropp \& Pettigrew 2005). In addition, it should be noted that we focused on an especially effective form of direct contact, i.e. direct cross-group friendships (Davies et al., 2011), which may explain why the STE emerged also among the minority group.

For the first time in the literature, we show that the STE also emerges as an outcome of extended contact. Notably, this effect was found among minority group members. This finding is in line with literature showing that extended contact is also effective among minority groups (Vezzali et al., 2014; Zhou et al., 2018), and demonstrates the potential of extended contact to reduce prejudice among individuals from disadvantaged groups. Unexpectedly, extended contact did not allow the emergence of the STE for the majority group. This may be explained by the fact that majority members relied more on their actual, direct experiences with the minority group. Note that the correlation between direct and extended contact was rather high. In fact, the 
correlation for the two variables was .69 , much higher than the average correlation between direct and extended contact (.46; cf. Zhou et al., 2018): to the extent that the effects of direct contact are generally stronger than those of extended contact, the high correlation between the two variables, coupled with the fact that effects of direct contact have been shown to be stronger than those of extended contact (Christ et al., 2010), may have prevented the emergence of the STE effects for extended contact among majority group members. A complementary explanation may be that the effects of extended contact for the majority group are mediated by variables not included in the present study: note in fact that, in line with the STE, extended contact was correlated with morality of the secondary outgroup and with contact intentions towards the secondary outgroup among majority group members. Supportive of the STE for extended contact and of the greater role of direct contact, results of an additional model, where extended contact was tested among majority group members as a unique independent variable (therefore excluding direct contact) revealed evidence of the STE, mediated by the hypothesized mediators (see Figure 1$)^{3}$.

Replicating scarce evidence on direct (Brambilla et al., 2013; Vezzali et al., 2017) and extended contact (Vezzali et al., 2017), effects of both contact forms on outgroup attitudes (towards the primary outgroup) were mediated by outgroup morality perceptions. More relevant to the present research, direct and extended contact effects were mediated primarily by morality perceptions of the primary outgroup, and in turn morality perceptions of the secondary and attitudes towards the primary outgroup. It is possible, therefore, that perceived morality of the primary outgroup following contact helps to form an impression of this outgroup, and contributes to shaping morality perceptions of uninvolved outgroups. Probably, the latter association is favored by some degrees of similarity between the two outgroups (e.g., in terms of a 
superordinate identity as stigmatized groups) that allow the association between morality perceptions. Future research can include a similarity measure to empirically test this possibility. Given the importance and prominence of morality in impression formation (Brambilla \& Leach, 2014; Brambilla et al., 2011), we believe that this construct can have an important role in future interactions with the secondary outgroup.

It should be noted that perceived morality of the primary outgroup did not mediate the effects of direct contact in the minority group. This effect may depend at least in part on the low sample size (see below where we acknowledge limitations). In fact, among minority group members, direct contact was moderately correlated with morality of the primary outgroup. To explore our hypotheses less conservatively, we tested a further model, similar to the one presented in Figure 3, where however we excluded extended contact (which, due to the moderate correlation with direct contact, may reduce its effect; Zhou et al., 2018). Results revealed that direct contact was indirectly associated with the two outcome variables, via morality perceptions of the primary outgroup, and in turn morality perceptions of the secondary outgroup and attitudes towards the primary outgroup ${ }^{4}$.

An important aspect of our study, contributing to research on the STE, was the consideration, for the first time, of behavioral intentions as a measure to assess generalization to the secondary outgroup. Further expanding literature, we found that the STE also emerged for behavioral intentions, and specifically for intentions to have contact with the secondary outgroup. To the extent that intentions are the most proximal predictor of actual behavior (Fishbein \& Ajzen, 1974), and that contact intentions lead to formation of cross-group friendships over time (Vezzali, Stathi, Giovannini, Capozza, \& Visintin, 2015), we believe these findings are encouraging. 
We also acknowledge some limitations in the present study. First, results are based on correlational evidence, as is the case with much of the STE literature. However, although this is the first study to test outgroup morality perceptions as the mediating mechanism for the STE, the prediction and findings are in line with previous cross-sectional evidence on outgroup morality as a mediator of contact effects (Brambilla et al., 2013; Vezzali et al., 2017), as well as with longitudinal (Eller \& Abrams, 2004; Tausch et al., 2010; Van Laar et al., 2005) and experimental (Shook et al., 2016) evidence. In order to better understand the underlying psychological processes of the STE, future research needs to examine the independent STEs for direct and extended contact in longitudinal and experimental studies. Second, the effects obtained may be specific to the groups we considered and cannot necessarily generalize to other intergroup contexts. Such generalization remains to be tested. Additionally, the sample size of minority group participants was rather small. This limits the interpretation and generalization of these findings to other contexts. Therefore, we acknowledge that it is important to replicate these findings with larger samples. As an additional point, in our research we relied on the information provided by the school regarding which participants were of immigrant origin. We did not assess whether immigrant participants self-identified as Italians and did not take into consideration the length of their stay in Italy. This may pose a limitation as acculturation variables and selfperceptions can, to an extent, influence immigrants' attitudes (Zick, Wagner, Van Dick, \& Petzel, 2002). Therefore, future research can explore the perspective of immigrant groups more thoroughly. Finally, attitudes towards primary and secondary outgroups were assessed with a similar scale. Although we are confident of the validity of our results having acquired similar findings with the other outcome variable (contact intentions towards the secondary outgroup), 
future studies should nonetheless use different measures to reduce the risk of shared method variance.

\section{Conclusion}

In this study we showed that the secondary transfer effect not only emerges for majority group members as an outcome of direct contact but also for minority group members, for both direct and extended contact. Furthermore, perceptions of outgroup morality are a mechanism driving STE, operating in association with intergroup attitudes. Understanding the mechanisms and boundaries of the STE in both majority and minority groups will inform educators and practitioners about the design of interventions that target the growing diversity in today's society, across categories such as ethnicity, religion, sexual orientation, and health, in order to promote tolerance and positive attitudes. 


\section{Footnotes}

1. Measures were part of a larger dataset. Other measures of the dataset, not included in the present article, were used to test other types of models and have been published in Vezzali et al. (2017).

2. Results presented are virtually the same when gender is not controlled for.

3. Results for this alternative model are not presented in the text, and are available upon request to the first author.

4. Results for this alternative model are not presented in the text, and are available upon request to the first author. 


\section{Data sharing}

Data and material used are available upon request to the first author.

\section{Conflict of interest}

The authors declare that there are no potential conflicts of interest with respect to the research, authorship, and/or publication of this article.

\section{Compliance with Ethical Standards}

The manuscript adheres to ethical guidelines specified in the APA Code of Conduct as well as the ethical guidelines of the university in which the research was conducted. 


\section{References}

Akaike, H. (1987). Factor analysis and AIC. Psychometrika, 3, 317-332.

doi:10.1007/BF02294359

Al Ramiah, A., Schmid, K., Hewstone, M., \& Floe, C. (2015). Why are all the White (Asian) kids sitting together in the cafeteria? Resegregation and the role of intergroup attributions and norms. British Journal of Social Psychology, 54, 100-124. doi:10.1111/bjso.12064

Allport, G. W. (1954). The nature of prejudice. Cambridge, MA: Addison-Wesley.

Birtel, M. D., Reimer, N. K., Wölfer R., \& Hewstone, M. (2019). Change in ethnic diversity and intergroup relations: The transition from segregated to mixed school for majority and minority students. European Journal of Social Psychology.

Birtel, M. D., Vezzali, L., \& Stathi, S. (2018). Extended contact and affective factors: A review and suggestions for future research. Testing, Psychometrics, Methodology in Applied Psychology, 2, 213-238. doi:10.4473/TPM25.2.4

Brambilla, M., Biella, M., \& Freeman, J.B. (2018). The influence of visual context on the evaluation of facial trustworthiness. Journal of Experimental Social Psychology, 78, 34-42. doi:10.1016/j.jesp.2018.04.011

Brambilla, M., Carraro, L., Castelli, L., \& Sacchi, S. (2019). Changing impressions: Moral character dominates impression updating. Journal of Experimental Social Psychology, 82, 6473. doi:10.1016/j.jesp.2019.01.003

Brambilla, M., Hewstone, M., \& Colucci, F. P. (2013). Enhancing moral virtues: Increased perceived outgroup morality as a mediator of intergroup contact effects. Group Processes and Intergroup Relations, 16, 648-657. doi:10.1177/1368430212471737 
Brambilla, M., \& Leach, C. W. (2014). On the importance of being moral: The distinctive role of morality in social judgment. Social Cognition, 32, 397-408. doi:10.1521/soco.2014.32.4.397

Brambilla, M., Rusconi, P., Sacchi, S., \& Cherubini, P. (2011). Looking for honesty: The primary role of morality (vs. sociability and competence) in information gathering. European Journal of Social Psychology, 41, 135-143. doi:10.1002/ejsp.744

Brambilla, M., Sacchi, S., Menegatti, M., \& Moscatelli, S. (2016). Honesty and dishonesty don't move together: Trait content information influences behavioral synchrony. Journal of Nonverbal Behavior, 40, 171-186. doi:10.1007/s10919-016-0229-9

Brambilla, M., Sacchi, S., Pagliaro, S., \& Ellemers, N. (2013). Morality and intergroup relations: Threats to safety and group image predict the desire to interact with outgroup and ingroup members. Journal of Experimental Social Psychology, 49, 811-821. doi:10.1016/j.jesp.2013.04.005

Brambilla,, M., Sacchi, S., Rusconi, P., \& Cherubini, P., \& Yzerbyt, V.Y. (2012). You want to give a good impression? Be honest! Moral traits dominate group impression formation. British Journal of Social Psychology, 51, 149-166. doi:10.1111/j.20448309.2010.02011.x

Brylka, A., Jasinskaja-Lahti, I., \& Mahonen, T. A. (2016). The majority influence on interminority attitudes: The secondary transfer effect of positive and negative contact. International Journal of Intercultural Relations, 50, 76-88. doi:10.1016/j.jintrel.2015.12.007 Chang, L. W., Krosch, A. R., \& Cikara, M. (2016). Effects of intergroup threat on mind, brain, and behavior. Current Opinion in Psychology, 11, 69-73. doi:10.1016/j.copsyc.2016.06.004 
Crisp, R. J., \& Turner, R. N. (20132012). Imagined intergroup contact: Refinements, debates, and clarifications. In G. Hodson \& M. Hewstone (Eds.), Advances in intergroup contact (pp. 135-151). London, UK: Psychology Press. doi:10.1016/B978-0-12-394281-4.00003-9

Davies, K., Tropp, L. R., Aron, A., Pettigrew, T. F., \& Wright, S. C. (2011). Cross-group friendships and intergroup attitudes: A meta-analytic review. Personality and Social Psychology Review, 15, 332-351. doi:10.1177/1088868311411103

De Carvalho-Freitas, M. N., \& Stathi, S. (2017). Reducing workplace bias toward people with disabilities with the use of imagined contact. Journal of Applied Social Psychology, 47, 256266. doi:10.1111/jasp. 12435

Eller, A., \& Abrams, D. (2004). Come together: Longitudinal comparisons of Pettigrew's reformulated intergroup contact model and the common ingroup identity model in AngloFrench and Mexican-American contexts. European Journal of Social Psychology, 34, 229256. doi:10.1002/ejsp.194

Fishbein, M., \& Ajzen, I. (1974). Attitudes towards objects as predictors of single and multiple behavioural criteria. Psychological Review, 8, 59-74. doi:10.1037/h0020074

Fritz, M. S., \& MacKinnon, D. P. (2007). Required sample size to detect the mediated effect. Psychological Science, 18, 233-239. doi:10.1111/j.1467-9280.2007.01882.x

Giovannini, D., \& Vezzali, L. (2011). Contact with immigrant parents as a predictor of teachers' attitudes and acculturation orientations toward immigrant children. International Journal about Parents in Education, 5, 65-76.

Haddock, G., Zanna, M. P., \& Esses, V. M. (1993). Assessing the structure of prejudicial attitudes: The case of attitudes toward homosexuals. Journal of Personality and Social Psychology, 65, 1105-1118. doi:10.1037/0022-3514.65.6.1105 
Harwood, J., Paolini, S., Joyce, N., Rubin, M., \& Arroyo, A. (2011). Secondary transfer effects from imagined contact: Group similarity affects the generalization gradient. British Journal of Social Psychology, 50, 180-189. doi:10.1348/014466610X524263

Hu, L., \& Bentler, P. M. (1999). Cut-off criteria for fit indexes in covariance structure analysis: Conventional criteria versus new alternatives. Structural Equation Modeling, 6, 1-55. doi:10.1080/10705519909540118

Jöreskog, K. G., \& Sörbom, D. (2007). LISREL 8.8 for Windows [Computer Software]. Lincolnwood, IL: Scientific Software International, Inc.

Joyce, N., \& Harwood, J. (2014). Improving intergroup attitudes through televised vicarious intergroup contact: Social cognitive processing of ingroup and outgroup information. Communication Research, 41, 627-643. doi:10.1177/0093650212447944

Kline, R. B. (1998). Principles and practice of structural equation modeling. New York, NY: Guilford Press.

Leach, C. W., Ellemers, N., \& Barreto, M. (2007). Group virtue: The importance of morality (vs. competence and sociability) in the positive evaluation of ingroups. Journal of Personality and Social Psychology, 93, 234-249. doi:10.1037/0022-3514.93.2.234

Little, T. D., Cunningham, W. A., Shahar, G., \& Widaman, K. F. (2002). To parcel or not to parcel: Exploring the question, weighing the merits. Structural Equation Modeling, 9, 151173. doi:10.1207/S15328007SEM0902_1

Lolliot, S., Fell, B., Schmid, K., Woelfer, R., Swart, H., Voci, A...\& Hewstone, M. (2015). Measures of intergroup contact. In G. Boyle, D. H. Saklofske, \& G. Matthews (Eds.), Measures of personality and social psychological constructs (pp. 652-683). San Diego, CA: Academic Press. 
Lolliot, S., Schmid, K., Hewstone, M., Al Ramiah, A., Tausch, N., \& Swart, H. (2013).

Generalized effects of intergroup contact: The secondary transfer effect. In G. Hodson \& M. Hewstone (Eds.), Advances in intergroup contact (pp. 81-112). London, UK: Psychology Press.

Mackie, D. M., Devos, T., \& Smith, E. R. (2000). Intergroup emotions: Explaining offensive behavioural tendencies in an intergroup context. Journal of Personality and Social Psychology, 79, 602-616. doi:10.1037//0022-3514.79.4.602

Mahonen, T. A., \& Jasinskaja-Lahti, I. (2016). Ramifications of positive and negative contact experiences among remigrants from Russia to Finland. Cultural Diversity and Ethnic Minority Psychology, 22, 247-255. doi:10.1037/cdp0000059

Meleady, R., \& Forder, L. (2018). When contact goes wrong: Negative intergroup contact promotes generalized outgroup avoidance. British Journal of Social Psychology. doi:10.1177/1368430218761568

Miles, E., \& Crisp, R. J. (2014). A meta-analytic test of the imagined contact hypothesis. Group Processes and Intergroup Relations, 17, 3-26. doi:10.1177/1368430213510573

Pettigrew, T. F. (1997). Generalized intergroup contact effects on prejudice. Personality and Social Psychology Bulletin, 23, 173-185. doi:10.1177/0146167297232006

Pettigrew, T. F. (1998). Intergroup contact theory. Annual Review of Psychology, 49, 65-85. doi:10.1146/annurev.psych.49.1.65

Pettigrew, T. F. (2009). Secondary transfer effect of contact: Do intergroup contact effects spread to noncontacted outgroups? Social Psychology, 40, 55-65. doi:10.1027/1864-9335.40.2.55

Pettigrew, T. F., \& Tropp, L. R. (2006). A meta-analytic test of intergroup contact theory. Journal of Personality and Social Psychology, 90, 751-783. doi:10.1037/0022-3514.90.5.751 
Pettigrew, T. F., \& Tropp, L. R. (2008). How does intergroup contact reduce prejudice? Metaanalytic tests of three mediators. European Journal of Social Psychology, 38, 922-934. doi:10.1002/ejsp.504

Rodriguez Mosquera, P. M., Manstead, A. S. R., \& Fischer, A. H. (2002). The role of honour concerns in emotional reactions to offences. Cognition and Emotion, 16, 143-163. doi:10.1080/02699930143000167

Schmid, K., Hewstone, M., Kupper, B., Zick, A., \& Wagner, U. (2012). Secondary transfer effects of intergroup contact: A cross-national comparison in Europe. Social Psychology Quarterly, 75, 28-51. doi:10.1177/0190272511430235

Schmid, K., Hewstone, M., \& Tausch, N. (2013). Secondary transfer effects of intergroup contact via social identity complexity. British Journal of Social Psychology, 53, 443-462. doi:10.1111/bjso.12045

Schwartz, S. H. (1992). Universals in the content and structure of values: Theoretical advances and empirical tests in 20 countries. In M. P. Zanna (Ed.), Advances in experimental social psychology (Vol. 25, pp. 1-65). NewYork, NY: Academic Press. doi:10.1016/S00652601(08)60281-6

Shook, N. J., Opkins, P. D., \& Koech, J. M. (2016). The effect of intergroup contact on secondary group attitudes and social dominance orientation. Group Processes and Intergroup Relations, 19, 328-342. doi:10.1177/1368430215572266

Stephan, W. G., \& Stephan, C. W. (1985). Intergroup anxiety. Journal of Social Issues, 41, 157175. doi:10.1111/j.1540-4560.1985.tb01134.x

Stephan, W. G., \& Stephan, C. W. (2000). An integrated theory of prejudice. In S. Oskamp (Ed.), Reducing prejudice and discrimination (pp. 23-45). Mahwah, NJ: Erlbaum. 
Tausch, N., Hewstone, M., Kenworthy, J. B., Psaltis, C., Schmid, K., Popan, J. R...\& Hughes, J. (2010). Secondary transfer effects of intergroup contact: Alternative accounts and underlying processes. Journal of Personality and Social Psychology, 99, 282-302. doi:10.1037/a0018553

Tausch, N., Hewstone, M., Schmid, K., Hughes, J., \& Cairns, E. (2011). Extended contact as a function of closeness of relationship with ingroup contacts. Group Processes and Intergroup Relations, 14, 239-254. doi:10.1177/1368430210390534

Trawalter, S., Richeson, J. A., \& Shelton, J. N. (2009). Predicting behavior during interracial interactions: A stress and coping approach. Personality and Social Psychology Review, 13, 243-268. doi:10.1177/1088868309345850

Tropp, L. R., \& Pettigrew, T. F. (2005). Relationships between intergroup contact and prejudice among minority and majority status groups. Psychological Science, 16, 951-957.

doi:10.1111/j.1467-9280.2005.01643.x

Turner, R. N., Hewstone, M., Voci, A., Paolini, S., \& Christ, O. (2007). Reducing prejudice via direct and extended cross-group friendship. European Review of Social Psychology, 18, 212255. doi:10.1080/10463280701680297

Turner, R. N., Hewstone, M., Voci, A., \& Vonofakou, C. (2008). A test of the extended contact hypothesis: The mediating role of intergroup anxiety, perceived ingroup and outgroup norms, and inclusion of the outgroup in the self. Journal of Personality and Social Psychology, 95, 843-860. doi:10.1037/a0011434

Turner, R. N., West, K., \& Christie, Z. (2013). Outgroup trust, intergroup anxiety, and outgroup attitude as mediators of the effect of imagined intergroup contact on intergroup behavioural tendencies. Journal of Applied Social Psychology, 43, E196-E205. doi:10.1111/jasp.12019 
United Nations (2015, December). Trends in international migration, 2015. United Nations Department of Economic and Social Affairs, Population Division. Retrieved June, 27, 2018, from

https://www.un.org/en/development/desa/population/migration/publications/populationfacts/d ocs/MigrationPopFacts20154.pdf

Van Laar, C., Levin, S. \& Sinclair, S., Sidanius, J. (2005). The effect of university roommate contact on ethnic attitudes and behavior. Journal of Experimental Social Psychology, 41, 329345. doi:10.1016/j.jesp.2004.08.002

Vezzali, L., Brambilla, M., Giovannini, D., \& Colucci, F. P. (2017). Strengthening purity: Moral purity as a mediator of direct and extended contact on sexual prejudice. Journal of Homosexuality, 64, 716-730. doi:10.1080/00918369.2016.1196998

Vezzali, L., Di Bernardo, G. A., Stathi, S., Cadamuro, A., Lasticova, B., \& Andraščiková, S. (2018). Secondary transfer effect among children: The role of social dominance orientation and outgroup attitudes. British Journal of Social Psychology, 57, 547-566. doi:10.1111/bjso. 12248

Vezzali, L. \& Giovannini, D. (2012). Secondary transfer effect of intergroup contact: The role of intergroup attitudes, intergroup anxiety and perspective-taking. Journal of Community and Applied Social Psychology, 22, 125-144. doi:10.1002/casp.1103

Vezzali, L., Hewstone, M., Capozza, D., Giovannini, D., \& Wölfer, R. (2014). Improving intergroup relations with extended and vicarious forms of indirect contact. European Review of Social Psychology, 25, 314-389. doi:10.1080/10463283.2014.982948

Vezzali, L., \& Stathi, S. (2017). Intergroup contact theory: Recent developments and future directions. Abingdon, UK: Routledge. 
Vezzali, L., Stathi, S., Giovannini, D., Capozza, D., \& Visintin, E. P. (2015). “And the best essay is...": Extended contact and cross-group friendships at school. British Journal of Social Psychology, 54, 601-615. doi:10.1111/bjso.12091

Visintin, E. P., Birtel, M. D., \& Crisp, R. J. (2017). The role of multicultural and colorblind ideologies and typicality in imagined contact interventions. International Journal of Intercultural Relations, 59, 1-8. doi:10.1016/j.ijintrel.2017.04.010

World Health Organization (2018). Disability and health. Retrieved June, 27, 2018, from http://www.who.int/news-room/fact-sheets/detail/disability-and-health

Wright, S. C., Aron, A., McLaughlin-Volpe, T., \& Ropp, S. A (1997). The extended contact effect: Knowledge of cross-group friendships and prejudice. Journal of Personality and Social Psychology, 73, 73-90. doi:10.1037/0022-3514.73.1.73

Zick, A., Wagner, U., Van Dick, R., \& Petzel, T. (2002). Acculturation and prejudice in Germany: Majority and minority perspectives. Journal of Social Issues, 57, 541-557. doi:10.1111/00224537.00228

Zhou, S., Page-Gould, E., Aron, A., Moyer, A., \& Hewstone, M. (2018). The Extended Contact Hypothesis: A Meta-Analysis on 20 Years of Research. Personality and Social Psychology Review, 1-29. doi:10.1177/1088868318762647 
Table 1. Means (standard deviations) of the constructs.

\begin{tabular}{lcccc}
\hline \hline \multicolumn{1}{c}{ Measures } & $\begin{array}{c}\text { Majority } \\
(N=422)\end{array}$ & $\begin{array}{c}\text { Minority } \\
(N=130)\end{array}$ & $t(550)$ & Cohen's $d$ \\
\hline Direct contact with the primary outgroup & $2.95(1.05)$ & $4.15(1.00)$ & $11.58^{* * *}$ & 1.17 \\
Extended contact with the primary outgroup & $3.51(1.06)$ & $3.94(1.13)$ & $3.95^{* * *}$ & 0.39 \\
Direct contact with the secondary outgroup & $1.58(0.52)$ & $1.48(0.54)$ & $2.07 *$ & 0.19 \\
Extended contact with the secondary outgroup & $1.93(0.71)$ & $1.83(0.78)$ & 1.47 & 0.13 \\
Morality of the primary outgroup & $2.69(1.02)$ & $3.00(0.82)$ & $3.54^{* * *}$ & 0.33 \\
Morality of the secondary outgroup & $3.93(0.86)$ & $3.58(1.04)$ & $3.48^{* * *}$ & 0.37 \\
Attitudes towards the primary outgroup & $57.27(25.15)$ & $69.27(23.33)$ & $4.84^{* * *}$ & 0.49 \\
Attitudes towards the secondary outgroup & $68.70(22.60)$ & $67.89(25.44)$ & 0.35 & 0.04
\end{tabular}

Note. All measures had a 5-step scale with the exception of the attitudes scales, which ranged from 0 to 100.

$* p<.05 . * * * p<.001$. 
Table 2. Zero-order correlations between the constructs for the majority, below the diagonal $(N=422)$, and for the minority, above the diagonal $(N=130)$.

\begin{tabular}{|c|c|c|c|c|c|c|c|c|c|c|}
\hline & & 1 & 2 & 3 & 4 & 5 & 6 & 7 & 8 & 9 \\
\hline 1. & Direct contact with the primary outgroup & - & $.58 * * *$ & $.21 *$ & $.25 * *$ & $.34 * * *$ & $.43 * * *$ & $.45^{* * *}$ & $.17 *$ & $.28 * * *$ \\
\hline 2. & $\begin{array}{l}\text { Extended contact with the primary } \\
\text { outgroup }\end{array}$ & $.69 * * *$ & - & $.27 * *$ & $.34 * * *$ & $.43 * * *$ & $.32 * * *$ & $.32 * * *$ & .12 & $.30 * * *$ \\
\hline 3. & Direct contact with the secondary outgroup & $.14 * *$ & $.10 *$ & - & $.69 * * *$ & $.20 *$ & .11 & .07 & .09 & $.27 * *$ \\
\hline 4. & $\begin{array}{l}\text { Extended contact with the secondary } \\
\text { outgroup }\end{array}$ & $.17 * * *$ & $.25 * * *$ & $.61 * * *$ & - & $.28 * * *$ & $.19^{*}$ & .13 & .08 & $.36^{* * *}$ \\
\hline 5. & Morality of the primary outgroup & $.30 * * *$ & $.24 * * *$ & .01 & $.12 *$ & - & $.43 * * *$ & $.42 * * *$ & $.32 * * *$ & $.41 * * *$ \\
\hline 6. & Morality of the secondary outgroup & .09 & $.15^{*}$ & -.02 & $.12 *$ & $.23 * * *$ & - & $.29 * * *$ & $.42 * * *$ & $.50 * * *$ \\
\hline 7. & Attitudes towards the primary outgroup & $.39 * * *$ & $.26^{* * *}$ & .05 & $.10^{*}$ & $.61 * * *$ & $.16^{* * *}$ & - & $.37 * * *$ & $.25 * *$ \\
\hline 8. & Attitudes towards the secondary outgroup & $.10^{*}$ & .08 & $.12 *$ & $.14 * *$ & $.22 * * *$ & $.19^{* * *}$ & $.37 * * *$ & - & $.43 * * *$ \\
\hline 9. & $\begin{array}{l}\text { Contact intentions towards the secondary } \\
\text { outgroup }\end{array}$ & $.18 * * *$ & $.18 * * *$ & $.25 * * *$ & $.26 * * *$ & $.25 * * *$ & $.22 * * *$ & $.27 * * *$ & $.46 * * *$ & - \\
\hline
\end{tabular}

$* p<.05 . * * p<.01 . * * * p<.001$. 
Table 3. Regression coefficients for the tested model for the Italian sample $(N=422)$.

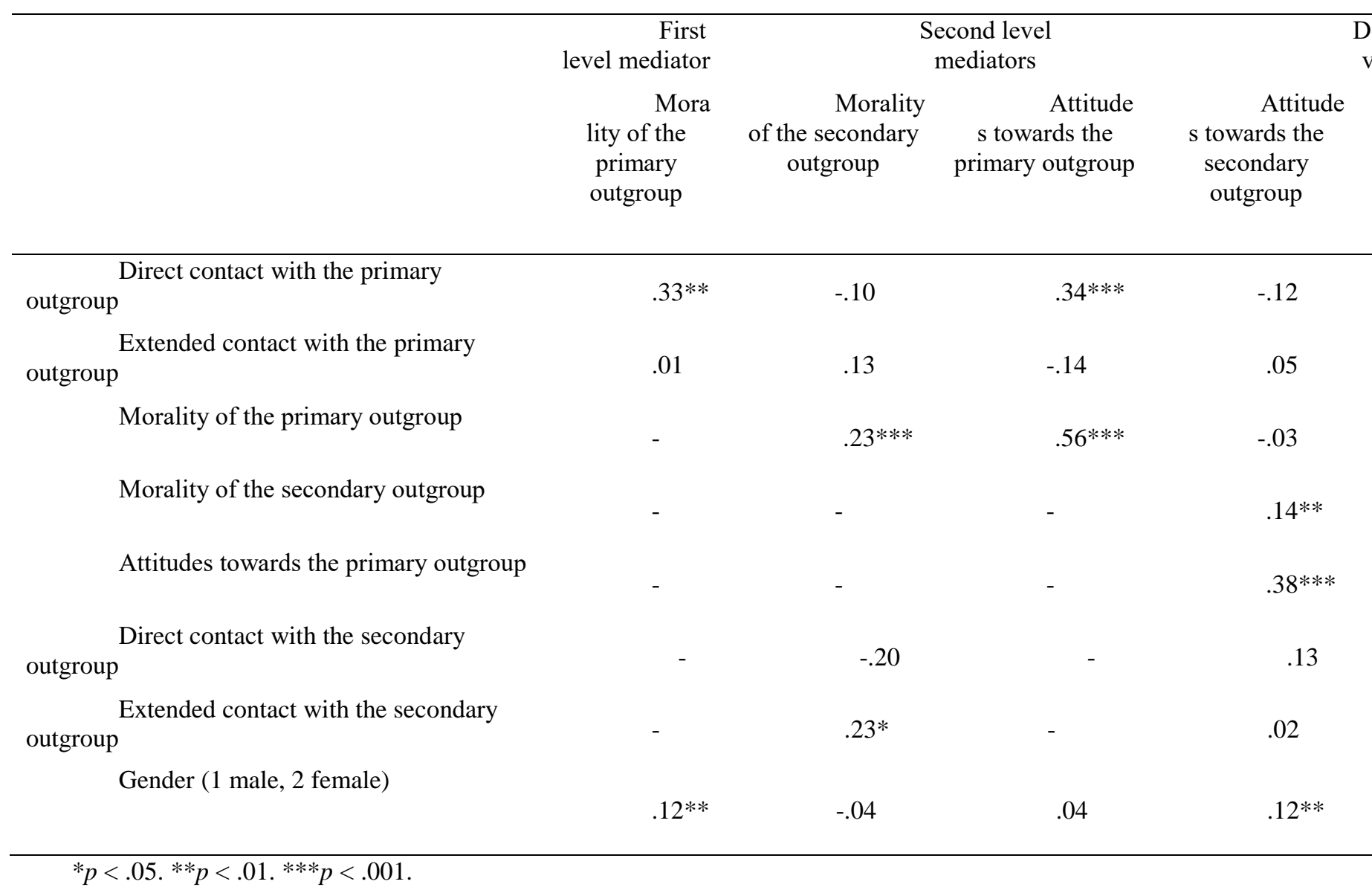


Table 4. Indirect effects in the hypothesized model for the Italian sample $(N=422)$.

\begin{tabular}{|c|c|c|c|c|c|}
\hline Predictor & First level mediator & $\begin{array}{l}\text { Second level } \\
\text { mediator }\end{array}$ & Dependent variable & $\begin{array}{c}\text { Mean } \\
\text { bootstrap } \\
\text { estimate }\end{array}$ & $\begin{array}{c}\text { Percentile } \\
\text { confidence interval } \\
(95 \%)\end{array}$ \\
\hline $\begin{array}{l}\text { Direct contact with } \\
\text { the primary outgroup }\end{array}$ & $\begin{array}{l}\text { Morality of the } \\
\text { primary outgroup }\end{array}$ & $\begin{array}{l}\text { Attitudes towards the } \\
\text { primary outgroup }\end{array}$ & $\begin{array}{l}\text { Contact intentions } \\
\text { towards the } \\
\text { secondary outgroup }\end{array}$ & 0.0274 & {$[0.0046,0.0653]$} \\
\hline $\begin{array}{l}\text { Direct contact with } \\
\text { the primary outgroup }\end{array}$ & $\begin{array}{l}\text { Morality of the } \\
\text { primary outgroup }\end{array}$ & $\begin{array}{l}\text { Attitudes towards the } \\
\text { primary outgroup }\end{array}$ & $\begin{array}{l}\text { Attitudes towards the } \\
\text { secondary outgroup }\end{array}$ & 1.6245 & {$[0.5704,3.0710]$} \\
\hline $\begin{array}{l}\text { Direct contact with } \\
\text { the primary outgroup }\end{array}$ & $\begin{array}{l}\text { Morality of the } \\
\text { primary outgroup }\end{array}$ & $\begin{array}{l}\text { Morality of the } \\
\text { secondary outgroup }\end{array}$ & $\begin{array}{l}\text { Contact intentions } \\
\text { towards the } \\
\text { secondary outgroup }\end{array}$ & 0.0120 & {$[0.0010,0.0344]$} \\
\hline $\begin{array}{l}\text { Direct contact with } \\
\text { the primary outgroup }\end{array}$ & $\begin{array}{l}\text { Morality of the } \\
\text { primary outgroup }\end{array}$ & $\begin{array}{c}\text { Morality of the } \\
\text { secondary outgroup }\end{array}$ & $\begin{array}{l}\text { Attitudes towards the } \\
\text { secondary outgroup }\end{array}$ & 0.2158 & {$[0.0063,0.6262]$} \\
\hline $\begin{array}{l}\text { Direct contact with } \\
\text { the primary outgroup }\end{array}$ & $\begin{array}{l}\text { Attitudes towards the } \\
\text { primary outgroup }\end{array}$ & ----- & $\begin{array}{l}\text { Contact intentions } \\
\text { towards the } \\
\text { secondary outgroup }\end{array}$ & 0.0521 & {$[0.0105,0.1236]$} \\
\hline $\begin{array}{l}\text { Direct contact with } \\
\text { the primary outgroup }\end{array}$ & $\begin{array}{l}\text { Attitudes towards the } \\
\text { primary outgroup }\end{array}$ & ----- & $\begin{array}{l}\text { Attitudes towards the } \\
\text { secondary outgroup }\end{array}$ & 3.0507 & {$[1.4216,5.6029]$} \\
\hline $\begin{array}{l}\text { Morality of the } \\
\text { primary outgroup }\end{array}$ & $\begin{array}{l}\text { Attitudes towards the } \\
\text { primary outgroup }\end{array}$ & ----- & $\begin{array}{l}\text { Contact intentions } \\
\text { towards the } \\
\text { secondary outgroup }\end{array}$ & 0.0876 & {$[0.0141,0.1627]$} \\
\hline $\begin{array}{l}\text { Morality of the } \\
\text { primary outgroup }\end{array}$ & $\begin{array}{l}\text { Attitudes towards the } \\
\text { primary outgroup }\end{array}$ & ----- & $\begin{array}{l}\text { Attitudes towards the } \\
\text { secondary outgroup }\end{array}$ & 5.1527 & {$[3.3318,7.3350]$} \\
\hline $\begin{array}{l}\text { Morality of the } \\
\text { primary outgroup }\end{array}$ & $\begin{array}{l}\text { Morality of the } \\
\text { secondary outgroup }\end{array}$ & ----- & $\begin{array}{l}\text { Contact intentions } \\
\text { towards the } \\
\text { secondary outgroup }\end{array}$ & 0.0372 & {$[0.0013,0.0770]$} \\
\hline $\begin{array}{l}\text { Morality of the } \\
\text { primary outgroup }\end{array}$ & $\begin{array}{l}\text { Morality of the } \\
\text { secondary outgroup }\end{array}$ & ----- & $\begin{array}{l}\text { Attitudes towards the } \\
\text { secondary outgroup }\end{array}$ & 0.678169 & {$[0.0266,1.6945]$} \\
\hline $\begin{array}{l}\text { Direct contact with } \\
\text { the primary outgroup }\end{array}$ & $\begin{array}{l}\text { Morality of the } \\
\text { primary outgroup }\end{array}$ & $\begin{array}{l}\text { Attitudes towards the } \\
\text { primary outgroup }\end{array}$ & ----- & 4.6873 & {$[1.5197,7.9436]$} \\
\hline $\begin{array}{l}\text { Direct contact with } \\
\text { the primary outgroup }\end{array}$ & $\begin{array}{l}\text { Morality of the } \\
\text { primary outgroup }\end{array}$ & $\begin{array}{c}\text { Morality of the } \\
\text { secondary outgroup }\end{array}$ & ----- & 0.0606 & {$[0.0132,0.1314]$} \\
\hline
\end{tabular}

Note: Mean bootstrap estimates are based on 5,000 bootstrap samples. 
Table 5. Regression coefficients for the tested model for the immigrant sample $(N=130)$.

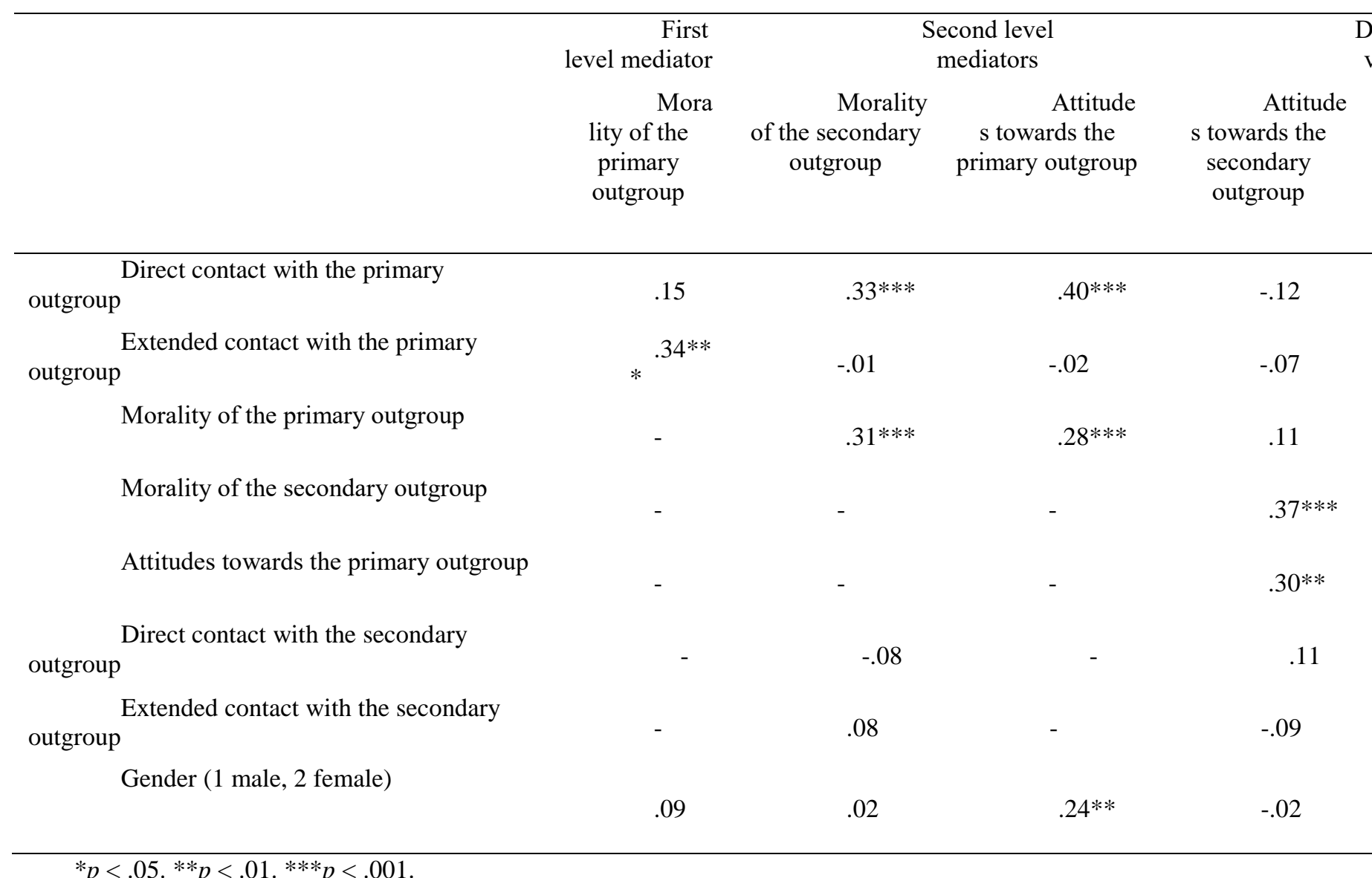


Table 6. Indirect effects in the hypothesized model for the immigrant sample $(N=130)$.

\begin{tabular}{|c|c|c|c|c|c|}
\hline Predictor & First level mediator & $\begin{array}{l}\text { Second level } \\
\text { mediator }\end{array}$ & Dependent variable & $\begin{array}{l}\text { Mean bootstrap } \\
\text { estimate }\end{array}$ & $\begin{array}{l}\text { Percentile confidence } \\
\text { interval }(95 \%)\end{array}$ \\
\hline $\begin{array}{l}\text { Extended contact } \\
\text { with the primary } \\
\text { outgroup }\end{array}$ & $\begin{array}{l}\text { Morality of the } \\
\text { primary outgroup }\end{array}$ & $\begin{array}{c}\text { Morality of the } \\
\text { secondary outgroup }\end{array}$ & $\begin{array}{l}\text { Contact intentions } \\
\text { towards the } \\
\text { secondary outgroup }\end{array}$ & 0.0330 & {$[0.0012,0.1411]$} \\
\hline $\begin{array}{l}\text { Extended contact } \\
\text { with the primary } \\
\text { outgroup }\end{array}$ & $\begin{array}{l}\text { Morality of the } \\
\text { primary outgroup }\end{array}$ & $\begin{array}{c}\text { Morality of the } \\
\text { secondary outgroup }\end{array}$ & $\begin{array}{l}\text { Attitudes towards the } \\
\text { secondary outgroup }\end{array}$ & 0.7333 & {$[0.0637,3.6614]$} \\
\hline $\begin{array}{l}\text { Extended contact } \\
\text { with the primary } \\
\text { outgroup }\end{array}$ & $\begin{array}{l}\text { Morality of the } \\
\text { primary outgroup }\end{array}$ & $\begin{array}{l}\text { Attitudes towards the } \\
\text { primary outgroup }\end{array}$ & $\begin{array}{l}\text { Attitudes towards the } \\
\text { secondary outgroup }\end{array}$ & 0.5258 & {$[0.0565,3.9118]$} \\
\hline $\begin{array}{l}\text { Direct contact with } \\
\text { the primary outgroup }\end{array}$ & $\begin{array}{c}\text { Morality of the } \\
\text { secondary outgroup }\end{array}$ & ----- & $\begin{array}{l}\text { Contact intentions } \\
\text { towards the } \\
\text { secondary outgroup }\end{array}$ & 0.1409 & {$[0.592,0.3006]$} \\
\hline $\begin{array}{l}\text { Direct contact with } \\
\text { the primary outgroup }\end{array}$ & $\begin{array}{c}\text { Morality of the } \\
\text { secondary outgroup }\end{array}$ & ----- & $\begin{array}{l}\text { Attitudes towards the } \\
\text { secondary outgroup }\end{array}$ & 3.0574 & {$[1.2186,7.0945]$} \\
\hline $\begin{array}{l}\text { Direct contact with } \\
\text { the primary outgroup }\end{array}$ & $\begin{array}{l}\text { Attitudes towards the } \\
\text { primary outgroup }\end{array}$ & ----- & $\begin{array}{l}\text { Attitudes towards the } \\
\text { secondary outgroup }\end{array}$ & 3.1408 & {$[1.2152,8.1074]$} \\
\hline $\begin{array}{l}\text { Morality of the } \\
\text { primary outgroup }\end{array}$ & $\begin{array}{c}\text { Morality of the } \\
\text { secondary outgroup }\end{array}$ & ----- & $\begin{array}{l}\text { Contact intentions } \\
\text { towards the } \\
\text { secondary outgroup }\end{array}$ & 0.1710 & {$[0.0763,0.3763]$} \\
\hline $\begin{array}{l}\text { Morality of the } \\
\text { primary outgroup }\end{array}$ & $\begin{array}{c}\text { Morality of the } \\
\text { secondary outgroup }\end{array}$ & ----- & $\begin{array}{l}\text { Attitudes towards the } \\
\text { secondary outgroup }\end{array}$ & 3.7728 & {$[1.5020,9.5768]$} \\
\hline $\begin{array}{l}\text { Morality of the } \\
\text { primary outgroup }\end{array}$ & $\begin{array}{l}\text { Attitudes towards the } \\
\text { primary outgroup }\end{array}$ & ----- & $\begin{array}{l}\text { Attitudes towards the } \\
\text { secondary outgroup }\end{array}$ & 2.6031 & {$[1.0142,6.3756]$} \\
\hline $\begin{array}{l}\text { Extended contact } \\
\text { with the primary } \\
\text { outgroup }\end{array}$ & $\begin{array}{l}\text { Morality of the } \\
\text { primary outgroup }\end{array}$ & $\begin{array}{c}\text { Morality of the } \\
\text { secondary outgroup }\end{array}$ & ----- & 0.0796 & {$[0.0128,0.2326]$} \\
\hline $\begin{array}{l}\text { Extended contact } \\
\text { with the primary } \\
\text { outgroup }\end{array}$ & $\begin{array}{l}\text { Morality of the } \\
\text { primary outgroup }\end{array}$ & $\begin{array}{l}\text { Attitudes towards the } \\
\text { primary outgroup }\end{array}$ & ----- & 1.6818 & {$[0.0684,6.4859]$} \\
\hline
\end{tabular}

Note: Mean bootstrap estimates are based on 5,000 bootstrap samples. 


\section{Figure captions \\ Figure 1}

Proposed theoretical model. In addition to the reported paths, also direct effects from contact with primary outgroup to first (i.e., primary outgroup morality) and second (i.e., secondary outgroup morality and primary outgroup attitudes) level mediators, and to the dependent variables (i.e., contact intentions and attitudes towards secondary outgroup), along with the correlations between the same level variables, have been estimated.

\section{Figure 2}

Path analysis with latent variables, Italian sample $(N=422)$. Standardized regression coefficients are shown. Only significant standardized paths are included.

Note. Direct contact with the secondary outgroup was associated with contact intentions towards the secondary outgroup $(\beta=.31, p<.01)$; extended contact with the secondary group was related to morality of the secondary outgroup $(\beta=.23, p<.05)$; gender $(1=$ male, $2=$ female $)$ was associated with morality of the primary outgroup $(\beta=.12, p<.01)$, and attitudes towards the secondary outgroup $(\beta=.12, p<.01)$.

$* p<.05 . * * p<.01 . * * * p<.001$.

\section{Figure 3}

Path analysis with latent variables, immigrant sample $(N=130)$. Standardized regression coefficients are shown. Only significant standardized paths are included.

Note. No significant associations were found between exogenous control variables (contact with the secondary outgroup) and morality of the secondary outgroup, and with contact intentions towards the secondary outgroup; gender $(1=$ male, 2 = female $)$ was associated with attitudes towards the primary outgroup $(\beta=.24, p<.01)$.

$* * p<.01 . * * * p<.001$. 